\title{
EKSISTENSI ANGKUTAN BECAK DALAM PERKEMBANGAN TRANSPORTASI DI YOGYAKARTA
}

Oleh: Yuni Astuti,SE,MM

AKPN “Bahtera" Yogyakarta

\begin{abstract}
ABSTRAKSI
Penelitian ini bertujuan untuk mengetahui apakah becak masih merupakan sarana transportasi alternatif dan faktor-faktor apa saja yang mempengaruhinya, serta untuk mengetahui sampai seberapa jauh faktor-faktor tersebut mempengaruhi becak sebagai sarana transportasi alternatif,dan faktor apa yang dominan mempengaruhinya.

Penelitian dengan mengambil sampel 100 responden tanpa melihat status sosial, tingkat pendidikan, tingkat pendapatan dll. Teknik penentuan sampel menggunakan metode teknik quota sampling yaitu teknik sampling yang tidak mendasarkan didi pada strata atau daerah tetapi mendasarkan diri pada jumlah yang sudah ditentukan. Analisa data mennggunakan metode regresi dan korelasi. Hasil penelitian diperoleh bahwa 91\% responden masih menggunakan becak sebagai sarana transportasi alternatif. Faktor harga, jarak, keunikan, kenyamanan dan kepentingan merupakan faktor-faktor yang mempengaruhi becak sebagai sarana transportasi alternatif. Faktor kepentingan merupakan faktor yang dominan mempengaruhi becak sebagai sarana transportasi alternatif yaitu sebesar 38,46\% dan juga mempunyai hubungan yang positif dan paling erat dalam mempengaruhi becak sebagai sarana transportasi alternatif serta mampu meningkatkan becak sebagai sarana transportasi alternatif paling besar. Kesimpulan : becak masih digunakan konsumen sebagai sarana transportasi alternatif yang berarti masih membantu pengemudi becak untuk bertahan hidup dari penghasilan yang diperolehnya.
\end{abstract}

Kata kunci: Becak, alternatif, konsumen

Abstract

This study aims to determine whether pedicabe is still an alternative transportation and any factors that influence it, as well as to determine to what extent these factors affect pedicabe as an alternative transportation and what is the dominant factor influencing it.

Research by taking a sample of 100 respondent, regardless of social status, education level, income level etc. Sampling technique using the method of quota sampling technique that is not based sampling technique it self on strata, or regions but basing on the number of pre determined. Data analysis using regression and correlation method. The result shows that 91\% respondent still use pedicabe as an alternative transportation. Price, distance, uniqueness, comfort and interest are all factors that affect pedicabe as an alternative transportation. Interest factor is the dominant factor affecting pedicabe as an alternative transportation. That is equal to $38,46 \%$ and also has positive relationship and most closely in influencing pedicabe as an alternative transportation and be able increase pedicabe as most of the alternative transportation. Conclusion: Pedicabe is still used by consumer as an alternative transportation means that transportation still helping Pedicabe driver to survive with earned income.

Key words: Pedicabe, alternative, consumer 


\section{PENDAHULUAN}

Kemajuan ilmu dan teknologi mendorong manusia untuk meningkatkan kualitas hidupnya baik dari segi material maupun spiritual. Peningkatan kualitas hidup diupayakan dari kegiatan perekonomian dimana kegiatan tersebut tidak terlepas dari penggunaan sumber daya alam baik darat, laut maupun udara.

Pemenuhan kebutuhan hidup manusia tidak terlepas dari penggunaan alat transportasi. Sarana transportasi digunakan untuk tercapainya hubungan di dalam masyarakat agar lebih mudah dan lancar.

Salah satu sarana transportasi yang ada di daerah-daerah adalah becak. Becak sebagai sarana transportasi tradisional sejak dulu cukup banyak membantu untuk memperlancar hubungan trasnportasi. Sejarawan Sartono Kartodirdjo (1981) yang mengatakan "Becak di Yogyakarta mulai muncul sebelum Perang Dunia II. Selama beberapa tahun setelah ditemukan, becak dapat diterima dengan baik sebagai alat transportasi, yaitu sebagai alat transportasi antar karesidenan dan tempat kerja di kota yang berskala medium." Becak juga merupakan salah satu alat transportasi yang ramah lingkungan karena tidak menggunakan tenaga mesin tetapi menggunakan tenaga manusia. Meskipun disadari saat sekarang ini sudah sangat tersaingi dengan kendaraan bermesin yang semakin banyak jumlahnya.

Yogyakarta yang dikenal sebagai kota budaya, kota wisata dan kota pendidikan juga memiliki sarana trasnportasi becak. Saat sekarang becak yang merupakan sarana transportasi sejak jaman dahulu mulai tersaingi keberadaannya dengan sarana transportasi bertenaga mesin lainnya. Namun sampai sekarang becak masih tetap bertahan. Hal ini menunjukkan bahwa becak memang masih dibutuhkan oleh masyarakat.

Becak yang mengandalkan tenaga manusia adalah masih manusiawi apabila pendapatan yang diterima pengemudi becak sesuai dengan tenaga yang telah dikeluarkannya. Jadi dengan menggunakan trasnportasi becak tidak bisa dikatakan mengeksploitasi tenaga manusia apabila konsumen lebih menghargai tenaga yang dikeluarkan pengemudi becak sesuai dengan harga, jarak, keunikan, kenyamanan dan kepentingan konsumen.

Keputusan untuk tetap menggunakan becak sebagai alat transportasi ataukah beralih ke alat trasnportasi lain dipengaruhioleh beberapa variabel yang ada pada becak yaitu harga, jarak, keunikan, kenyamanan dan kepentingan konsumen. 
Semua tergantung dari pilihan konsumen sendiri. Kosumen akan beralih ke sarana transportasi lain atau konsumen tetap terus menggunakan becak sebagai sarana transportasi yang berarti ikut mempertahankan dan menerima becak sebagai salah satu sarana trasnportasi darat mereka sekaligus membantu pengemudi becak untuk memperoleh penghasilan.

\section{METODOLOGI PENELITIAN}

Penelitian ini merupakan studi kasus bagi konsumen becak yang ada di Yogyakarta. Populasi penelitian ini adalah semua konsumen becak yang ada di Yogyakarta pada waktu penelitian ini dilakukan.

Teknik pengambilan sampel menggunakan teknik Quota sampling dan mengambil 100 responden yang berasal dari 6 kecamatan yang ada di Yogyakarta yaitu Mantrijeron, Mergangsan, Umbulharjo, Gedongtengan, Gondokusuman dan Gondomanan. Metode pengumpulan data menggunakan metode observasi, questioner dan interview. Metode analisa analisa kualitatif dan analisa kuantitatif. Alat analisa kuantitatif menggunakan Analisa regresi dan korelasi Berganda.

PEMBAHASAN

Sarana Transportasi Tidak Bermesin di Yogyakarta

Tabel 1.Data sarana Transportasi Tidak Bermesin di Yogyakarta

\begin{tabular}{|l|l|l|l|l|}
\hline NO & Keterangan & Tahun 1975 & Tahun 1995 & Tahun 2010 \\
\hline 1 & Becak & 4712 & 4515 & $\left.4500^{*}\right)$ \\
\hline 2 & Andong & 300 & 300 & 300 \\
\hline
\end{tabular}

(Sumber : Dinas Perhubungan Yogyakarta)

Dari data diatas jumlah becak dari tahun 1975 sampai dengan tahun 2010 cenderung sama, hanya untuk tahun 2010 jumlah 4500 becak tersebut adalah becak yang sudah memiliki Surat Ijin Operasional Kendaraan Tidak Bermotor (SIOKTB).Dan masih menunggu turunnya surat ijin ada sejumlah 2000 becak untuk seluruh Propinsi.

Becak sebagai salah satu sarana transportasi tidak bermesin dibatasi maksimal 8000 surat ijin saja karena untuk menghindari kemacetan yang ada di Yogyakarta. 
Berdasarkan surat ijin yang dikeluarkan oleh Dishub dalam 3 tahun relatif sama jumlahnya. Hal ini menunjukkan bahwa becak masih tetap bertahan hidup yang berarti masih digunakan sebagai sarana transportasi bagi konsumen.

\section{Becak Merupakan Sarana Transportasi Alternatif}

Becak merupakan sarana transportasi yang menggunakan tenaga manusia juga dikenal sebagai alat angkut yang dahulu dipergunakan oleh semua kalangan. Dewasa ini sudah banyak mendapat saingan dari sarana trasnportasi bermesin seperti kendaraan bermotor, bis kota, transjogja, taxi dan lain-lain. Namun kenyataannya becak keberadaannya masih ada sampai sekarang. Hal ini menunjukkan becak memang masih eksis. Meskipun becak untuk saat sekarang ini bukan lagi menjadi sarana tranportasi utama tapi keberadaannya masih tetap diakui oleh masyarakat.

Tabel 2.Becak Sebagai Sarana Transportasi Alternatif

\begin{tabular}{|c|c|c|}
\hline Keterangan & Jumlah & Prosentase \\
\hline Becak sebagai Alternatif & 91 & $91 \%$ \\
Becak bukan alternatif & 9 & $9 \%$ \\
\hline Jumlah & 100 & $100 \%$ \\
\hline
\end{tabular}

(sumber: Data hasil penelitian)

Berdasarkan data diatas diperoleh bahwa sebagain besar sampel yaitu sebanyak $91 \%$ masih menggunakan becak sebagai sarana trasnportasi alternatif

Dan hanya $9 \%$ sampel yang sudah tidak menggunakan becak sebagai sarana transportasi alternatif.

Tabel 3.Faktor Dominan yang Mempengaruhi Becak sebagai Sarana Trasnportasi Alternatif

\begin{tabular}{|l|l|l|}
\hline \multicolumn{1}{|c|}{ Keterangan } & \multicolumn{1}{c|}{ Jumlah } & \multicolumn{1}{c|}{ Prosentase } \\
\hline Harga & 8 & $8,79 \%$ \\
Jarak & 19 & $20,88 \%$ \\
Keunikan & 17 & $18,68 \%$ \\
Kenyamanan & 12 & $13,19 \%$ \\
Kepentingan & 35 & $38,46 \%$ \\
\hline Jumlah & 91 & $100 \%$ \\
\hline
\end{tabular}

(sumber: data hasil penelitian) 
Berdasarkan tabel diatas diperoleh bahwa sebagian dari responden yang memilih becak sebagai sarana trasnportasi alternatif sebagian besar memilih karena faktor kepentingannya yaitu sebesar $38,46 \%$. Yang memilih jarak sebagai faktor dominan yang mempengaruhi becak sebagai sarana transportasi alternatif bagi konsumen sebanyak 20,88\% . Dilihat dari keunikannya menduduki tempat ketiga yaittu sebanyak 18,68\%. Berdasarkan faktor kenyamanan hanya sebanyak $13,19 \%$, dan berdasarkan faktor harga menduduki tempat terakhir yaitu sebanyak 8,79\%.Disini konsumen menganggap harga tidak mempengaruhi pilihannya terhadap becak sebagai sarana trasnportasi alternatif. Harga biasanya berkaitan dengan jarak tempuh sehingga bila konsumen menempuh jarak yang agak jauh kemungkinan mereka akan memilih alternatif transportasi yang lain. Meskipun harga yang ditawarkan oleh pengemudi becak disesuaikan dengan jarak tempuh dan tenaga yang dikeluarkannya.

Analisa regresi menggunakan variabel dependen yang dinyatakan dengan variabel $Y$ yaitu becak sebagai sarana transportasi alternatif. Variabel independen dinyatakan dengan variabel $x$ yang terdiri dari lima variabel, dimana sebagai $x 1$ adalah harga, $x 2$ adalah jarak, $x 3$ adalah keunikan, $\mathrm{x} 4$ adalah kenyamanan dan $\mathrm{x} 5$ adalah kepentingan.

Berdasarkan pengolahan data dengan analisa linear berganda maka dapat diketahui sejauh mana faktor harga, jarak, keunkan, kenyamanan dan kepentingan mempengaruhi becak sebagai sarana transportasi alternatif.

$$
\begin{aligned}
& Y=-12,9644+1,3678 \times 1+1,6667 \times 2+1,6047 \times 3+1,5629 \times 4+2,2815 \times 5 \\
& \begin{array}{lllll}
(0,3054) \quad(0,3633) & (0,3044) \quad(0,3244) \quad(0,3614)
\end{array} \\
& \mathrm{t}=\quad(4,479) \quad(4,588) \quad(5,271) \quad(4,815) \quad(6,315)
\end{aligned}
$$

Multiple $\mathrm{R}=0,9056$

Multiple $\mathrm{R}=0,9056$ berarti bahwa hubungan antara $\times 1, \times 2, x 3, \times 34, \times 5$ terhadap $\mathrm{Y}$ adalah kuat. Berdasarkan hasil analisa statistik tersebut diatas diperoleh $\mathrm{R}^{2}=0,8201$ berarti bahwa faktor harga, jarak, keunikan, kenyamanan dan kepentingan secara bersama sama mempengaruhi becak sebagai saranatransportasi alternatif $(Y)$ sebesar $82 \%$ dan selebihnya sebasar $18 \%$ dipengaruhi faktor lain.

Berdasarkan uji statistik dengan tingkat kepercayaan sebesar 95\% diperoleh t hitung 4,479; 4,588; 5,271; 4,815; 6,315 lebih besar dari t tabel sebesar 1,98, berarti kelima faktor tersebut berpengaruh secara nyata terhadap becak sebagai sarana tranportasi alternatif, 
dan faktor kepentingan merupakan faktor yang paling berpengaruh nyata terhadap becak sebagai sarana tranportasi alternatif.

Berdasarkan persamaan regresi tersebut diatas dapat terlihat bahwa becak sebagai sarana tranportasi alternatif dipengaruhi oleh faktor kepentingan (x5), yang merupakan faktor yang paling dominan karena koefisien regresinya terbesar yaitu 2,2815. Artinya bahwa setia kenaikan satu stuan faktor kepentingan akan menaikkan becak sebagai sarana transportasi alternatif bagi konsumen sebesar 2,2815, dengan asumsi faktorOfaktor yang lain dianggap tetap. Selanjutnya faktor jarak (x2) dengan nilai 1,6667 yang berarti setiap kenaikan jarak satu satuan akan menaikkan becak sebagai sarana transportasi alternatif sebesar 1,6667. Mendudukitempat ketiga adalah keunikan (x3) dimana setiap kenaikan satu satuan faktor kepentingan akan menaikkan becak sebagai sarana transportasi alternatif sebesar 1,6047 dimana faktor lain dianggap tetap. Faktor kenyamanan meduduki tepat keempat dengan koefisien regresi sebesar 1,5629 berarti bahwa setiap kenaikan satu satuan faktor kenyamanan $=x 4$ akan mempengaruhi becak sebagai sarana transportasi alternatif. Faktor terakhir yang mempengaruhi becak sebagai sarana transportasi alternatif adalah harga $(x 1)$. Setiap kenaikan satu satuan faktor harga akan menaikkan becak sebagai sarana transportasi alternatif sebesar 1,3678 dengan asumsi faktor lain dianggap tetap.

Tabel 4. Hasil Analisa Korelasi

\begin{tabular}{|l|l|l|l|l|l|l|}
\hline & $\mathrm{Y}$ & $\mathrm{X} 1$ & $\mathrm{X} 2$ & $\mathrm{X3}$ & $\mathrm{X} 4$ & $\mathrm{X5}$ \\
\hline $\mathrm{Y}$ & 1.00000 & & & & & \\
\hline $\mathrm{X} 1$ & .51292 & 1.00000 & & & & \\
\hline $\mathrm{X} 2$ & .64150 & .33948 & 1.00000 & & & \\
\hline $\mathrm{X3}$ & .61619 & .17384 & .40856 & 1.00000 & & \\
\hline $\mathrm{X} 4$ & .62800 & .36247 & .34788 & .31248 & 1.00000 & \\
\hline X5 & .64286 & .17945 & .34108 & .32563 & .35075 & 1.00000 \\
\hline
\end{tabular}

(Sumber: Data olahan)

Bedasarkan analisa korelasi diatas diperoleh bahwa hubungan antara $\mathrm{x} 1$ (harga) dan $\mathrm{Y}$ sebesar 0,5129 atau sebesar 51,29\%, hubungan anatar x2 (jarak) sebesar 0,64150, hubungan antara $Y$ dengan $X 3$ (Keunikan) sebesar 0,61619, hubungan antara $Y$ dengan $x 4$ ( kenyamanan sebesar 0,62800 dan hubungan antara $Y$ dengan x5 (kepentingan) sebesar 
0,64286. Berarti kelima faktor tersebut diatas yang memiliki hubungan paling erat terhadap becak sebagai sarana transportasi alternatif adalah faktor kepentingan.

\section{KESIMPULAN DAN SARAN}

Angkutan becak dalam Perkembangan Transportasi di Yogyakarta tetap masih harus dipertahankan eksistensinya sebab:

Pertama, becak tetap masih dipergunakan sebagai sarana tranportasi alternatif meskipun bukan sebagai alat transportasi utama. Berarti becak cukup layak dipertahankan karena masih dibutuhkan konsumen.

Kedua, faktor- faktor yang mempengaruhi becak sebagai sarana transportasi alternatif adalah harga, jarak, keunikan, kenyaman dan kepentingan.

Ketiga, Faktor yang paling dominan mempengaruhi becak sebagai sarana transportasi alternatif adalah faktor kepentingan, baik dari analisa deskriptif maupun analisa regresi.

Keempat, berdasarkan analisa korelasi disimpulkan bahwa faktor harga, jarak, keunikan, kenyamanan dan kepentingan mempunyai hubungan yang positif dan erat terhadap becak sebagai sarana transportasi alternatif. Dan yang mempunyai hubungan paling erat adalah faktor kepentingan.

Masih eksisnya angkutan becak maka disarankan perlu adanya koordinasi diantara para pengemudi becak agar para pengemudi becak bisa meningkatkan taraf kehidupannya. Koordinasi yang dilakukan misalnya dengan mendirikan koperasi becak, yang salah satu fungsinya adalah untuk mengatur daerah kerja sehingga bisa memeratakan penghasilan pengemudinya. Selain itu koperasi yang didirikan ini juga bisa difungsikan untuk membantu pengemudi yang belum memiliki becak sendiri agar bisa memiliki becak sendiri dengan cara meminjam uang melalui koperasi tersebut.

Kepada seluruh penumpang ataupun konsumen becak diharapkan agar lebih menghargai tenaga yang telah dikeluarkan oleh pengemudi becak dengan memberikan imbalan yang sepantasnya. 


\section{Daftar Pustaka}

Djarwanto PS dan Pangestu Subagyo, Statistik Induktif ,BPFE Yogyakarta, Edisi Kelima.

Fandy Tjiptono, Pemasaran Jasa, Banyumedia Publishing JawaTimur,Edisi Ketiga, 2007

Moh . Nazir, Metode Penelitan,Penerbit Ghalia Indonesia, Cetakan ke enam, 2010

Philip Kotler, Manajemen Pemasaran, Analisis, Perencanaan dan Pengendalian, Penerbit Salemba Empat Jakarta, Jilid I dan Jilid II, 1998

Philip Kotler,Swee Hoon Ang, Siew Meng Leong, Ching Tiong Tan, Marketing Management An Asian Perspective, Prentice Hall Singapore, 1996 